\title{
The environmental perception of Law students: case study with freshmen and senior students in a private university in Manaus
}

\section{Mariane Vieira da Silva', José Heder Benatti²}

\begin{abstract}
1,2, Programa de Pós-Graduação em Ciência e Meio Ambiente do Instituto de Ciências Exatas e Naturais da Universidade Federal do Pará (PPGCMA/ICEN/UFPA). Bairro Guamá. CEP: 66075-110. Caixa Postal 479. PABX +55 91 3201 7000. Belém - Pará - Brasil.
\end{abstract}

Email: marianevs@ hotmail.com.br

Received: August $5^{\text {th }}, 2017$

Accepted: September 25th, 2017

Published: September $30^{\text {th }}, 2017$

Copyright $\odot 2016$ by authors and Institute of Technology Galileo of Amazon (ITEGAM) This work is licensed under the Creative Commons Attribution International

License (CC BY 4.0).

http://creativecommons.org/licenses/by/4.0/ (c) (1) (2) Opean Actes:

\begin{abstract}
This article aims to present a case study about the enviromental perception on law students, on freshmen and senior students, in a private university in Manaus/AM. The data, collected through a closed questionnaire have provided a detailed picture about their perception on environment legal concept and its professional qualification importance. The findings revealed the despite the students knowledge, they still need to improve their perception in real actions involving social-legalenviromental activities.
\end{abstract}

Keywords: Environment, Environmental Perception, Law, Environmental Concept

\section{A percepção ambiental de acadêmicos de Direito: um estudo de caso com calouros e formandos de uma faculdade particular de Manaus}

\section{RESUMO}

Este artigo tem como finalidade apresentar um estudo de caso sobre a percepção ambiental de alunos de Direito, com calouros e formandos, de uma faculdade particular de Manaus/AM. Os dados foram coletados através de um questionário fechado e ofereceram um diagnóstico da sua percepção do conceito legal de meio ambiente e da importância na formação profissional. Os resultados revelaram que mesmo com o conhecimento dos alunos, eles ainda precisam melhorar sua percepção em ações reais que envolvam atividades sócio-legal-ambientais..

Palavras-chave: Meio Ambiente, Percepção Ambiental, Direito, Conceito de meio ambiente.

\section{INTRODUÇÃO}

O estudo da percepção ambiental teve a sua evolução e importância ampliada a partir de 1973, quando a UNESCO criou o Projeto 13 - Man and biosphere reconhecendo como ferramenta válida e indicada para o planejamento das ações em meio ambiente [1]. Para [1] acrescenta que conhecer o grau de envolvimento com o meio ambiente é fundamental para entendermos a forma como a mente percebe a natureza.

Percepção ambiental é a tomada de consciência acerca do meio ambiente pelo indivíduo [2]. No campo educacional o seu estudo gera informações que podem servir de base para sensibilização e compreensão do meio ambiente a partir do desenvolvimento de percepção [1]. Frente a tantas mudanças ambientais que o planeta vem sofrendo é preciso que se formem profissionais cada vez mais atentos às causas ambientais. $\mathrm{Na}$ esfera jurídica não poderia ser diferente, [3] propõe que deve ser agregado um viés de realidade ao ensino classicamente positivista das letras jurídicas nas questões emergenciais ambientais

O estudo da percepção ambiental dos acadêmicos de Direito pode trazer informações que sirvam para agregar valor ao olhar desses futuros profissionais. E dar validade à abordagem pedagógica utilizada no decorrer da sua formação universitária, uma vez que a percepção é o somatório de experimentações, vivências e lições adquiridas [4].

Este estudo buscou reconhecer o olhar dos discentes sobre a sua própria percepção ambiental, a capacidade de identificá-la no currículo jurídico, o reconhecimento da importância desse tema na sua formação e se ao final do curso apresentam alguma intenção de atuação na área jurídicoambiental. 


\section{REFERENCIAL TEÓRICO}

Percepção é um termo que deriva do latim perception, traduz o ato de perceber, compreender, tomando consciência de dado fenômeno ou objeto. É o resultado de um contato particular e revela o modo de acesso que cada pessoa utiliza para incorporar o novo para si [5].

A doutrina conceitua percepção ambiental e indica como seu objetivo principal a compreensão de fatores e mecanismos que terminam levando o ser humano a olhar, sentir, agir e reagir de forma diferente em relação ao meio [2].

As pesquisas em percepção ambiental terminam por contribuir com o uso mais racional dos recursos naturais, com a participação de toda sociedade, com o desenvolvimento e planejamento regional, e, também, no registro e preservação das percepções e dos sistemas de conhecimento do ambiente [6].

O Direito como ciência social dinâmica tem nas leis e normas formas de representação no cotidiano social, assim, os conceitos e definições utilizados por ele também sofrem transformações conforme são adequados ao tempo e interesses da sociedade [7].

A compreensão e o conceito de meio ambiente sofrem adaptações a depender do contexto social, temporal e da identificação com a atividade degradante. Fomentar uma compreensão crítica da conceituação é uma atividade que necessita ser feita juntamente ao discurso de sustentabilidade e desenvolvimento sustentável agregando um olhar interdisciplinar aos avanços científicos da racionalidade e do saber ambiental [8].

É imprescindível que os paradigmas sejam mudados e o efeito antropogênico intrínseco seja inserido como parte obrigatória, não apenas da conceituação, como do desenvolvimento da degradação ambiental do planeta. A proposta de uma visão que não aliene os efeitos da relação do homem com o meio e que o leve a transmutar o seu pensamento de assimilação e finitude dos recursos naturais terrestres [9].

Assim, proteger o meio ambiente é proteger a própria sobrevivência do ser humano, e, para tutelar esse bem jurídico é preciso compreender as principais visões que o traduzem e a sua relação com o homem. Historicamente fincada em características antropocêntricas, nos dias atuais, vem passando por transformações sendo abrandada por um antropocentrismo mitigado que leva em conta o bem estar das gerações futuras e/ou dos animais. Apresentando também outro extremo, o nãoantropocentrismo, composto pelo biocentrismo e ecologismo que procuram focar na natureza como um todo, envolvendo seres humano e os meios abióticos [10].

$\mathrm{O}$ ensino jurídico precisa agora adequar-se à realidade $\mathrm{e}$ necessidades atuais, em busca de um modelo misto normativo com o intuito de superar os limites físicos e acadêmicos da Universidade e conjugar uma formação eclética, reflexiva crítica e prática no futuro profissional do acadêmico de Direito [11].

A aplicação de uma visão interdisciplinar ambiental no ensino do Direito precisa ser repensada de modo mais efetivo, atrativo e cativante à esfera acadêmica. É preciso repensar a academia e trabalhar ainda na universidade uma formação ambiental com o aluno de Direito o que possibilitaria a construção do senso crítico que se almeja em qualquer classe universitária [12].

A teoria deve estar ligada à prática, de forma que os problemas sociais sejam abordados em sala de aula "dando vida" à letra seca da lei. Assim, o ensino jurídico estaria preparando alunos para o universo além dos muros da Universidade, desenvolvendo capacidade crítica e transformadora direcionada ao bem universal comum, ou seja, o ambiente [13].

$\mathrm{O}$ estudo da percepção ambiental dos discentes acerca do tema meio ambiente possibilita compreender a capacidade que este tem de perceber que faz parte desse universo e com que olhar recebe essas informações na graduação, desse modo, adquirindo, ou não, a noção da responsabilidade ambiental geradora de uma participação atuante como cidadão e como futuro profissional.

\section{MATERIAIS E MÉTODOS}

A referida pesquisa utilizou a metodologia descritiva de natureza qualiquantitativa através da análise de um estudo de caso, onde os dados levantados ofereceram a oportunidade de quantificar e integrar uma leitura qualitativa das medidas obtidas. Houve uma prévia consulta bibliográfica e documental incluindo artigos científicos, teses, dissertações e periódicos nas áreas do Direito e Meio Ambiente.

O estudo foi realizado com calouros e formandos de Direito de uma universidade particular de Manaus, através da aplicação de um instrumento fechado in loco contendo perguntas de múltipla escolha. A faculdade à época tinha 1.472 alunos matriculados no curso, sendo destes, quarenta e seis (46) calouros e cento e cinquenta (150) formandos, e, para coleta e análise dos dados estudou-se um universo de $30 \%$ de cada grupo amostral.

A escolha desses dois grupos distintos foi justificada pela expectativa de comparar a evolução do conceito e das questões que envolvem o tema meio ambiente entre os alunos que ingressam e os que saem da instituição, e, ainda, observar se o entendimento da importância do estudo de questões ambientais na formação do profissional de Direito estava presente em algum dos dois grupos.

$\mathrm{O}$ instrumento principal continha questões que procuraram investigar além da qualificação dos entrevistados, também a sua percepção da presença do meio ambiente no seu cotidiano como cidadão e na sua formação como aluno de Direito. A última questão foi proposta no modelo de itens/proposições revelando o nível de concordância dos discentes em relação a temas ambientais sendo avaliadas com auxílio da escala Likert de 5 opções.

A opção pela escala de Likert justificou-se por ser a mais utilizada em mensurações de atitudes nas ciências ambientais, tendo como vantagem de ser de fácil manuseio no trabalho com o grau de concordância dos sujeitos sobre uma proposição qualquer [14].

Após a coleta, os dados do constructo foram tabulados com o auxílio do programa Microsoft Office EXCEL 2010. Foram feitas análises de estatística descritiva confirmando a variância, o desvio padrão e o coeficiente de variação dos dados obtidos, bem como, confirmado a coeficiente de confiabilidade do alfa de Cronbach gerando segurança para a leitura e interpretação das respostas.

\section{RESULTADOS E DISCUSSÕES.}

\section{IV.1 QUALIFICAÇÃO DO PERFIL DOS DISCENTES.}

As primeiras questões procuraram traçar um breve perfil dos discentes que participaram do estudo, quanto ao sexo e a idade desses participantes, como mostra a Tabela 1. Tem-se, em resumo, uma leve preponderância de mulheres sobre homens. Há entre os calouros uma quantidade bem expressiva de indivíduos jovens até 21 anos, que já era uma expectativa nessa pesquisa, frente a um grupo de formandos heterogêneo quanto à idade, mas, com uma quantidade significativa de elementos adultos com 31 anos ou mais. 
Tabela 1. Distribuição dos estudantes que participaram da pesquisa por sexo e idade.

\begin{tabular}{cccc}
\hline \multicolumn{2}{c}{ Característica dos estudantes } & Calouros $(\mathrm{n})$ & Formandos $(\mathrm{n})$ \\
\hline \multirow{2}{*}{ Sexo } & Feminino & 7 & 26 \\
& Masculino & 7 & 19 \\
& $18-21$ anos & 10 & 14 \\
\multirow{4}{*}{ Idade } & $22-24$ anos & 1 & 16 \\
& $25-27$ anos & 1 & 1 \\
& $28-30$ anos & 1 & 4 \\
\hline
\end{tabular}

Fonte: Autores, (2016).

\section{IV.2 PERCEPÇÃO AMBIENTAL: CONCEITO DE MEIO AMBIENTE.}

A proposta da quarta questão foi identificar como os discentes compreendem o conceito de meio ambiente e a abordagem escolhida envolveu a utilização de definição e termos comuns à esfera jurídica. Como proposições foram inseridos conceitos: legal, doutrinário e de abordagem complexa como demonstrado na Tabela 2.

Tabela 2. Relação das conceituações utilizadas.

PNMA - Art. $3^{\circ}$., I o conjunto de condições, leis, influências e interações de ordem física, química e biológica, que permite, abriga e rege a vida em todas as suas formas

Classificação - José constitui o espaço urbano construído, Afonso da Silva incluindo o conjunto de edificações, Meio ambiente espaço urbano fechado, e os artificial equipamentos públicos, que são as ruas, praças, áreas verdes, ou seja, espaço urbano aberto

Classificação - José o meio ambiente cultural, integrado pelo Afonso da Silva patrimônio histórico, artístico, Meio ambiente arqueológico, paisagístico, turístico, que, cultural embora artificial, em regra, como obra do homem, difere meio ambiente artificial pelo sentido de valor especial que adquiriu ou de que se impregnou

Classificação - José o meio ambiente natural ou físico, Afonso da Silva constituído pelo solo, a água, o ar Meio ambiente atmosférico, a flora, enfim, pela interação natural ou físico dos seres vivos e seu meio

Conceito filosófico - as relações complexas e sinérgicas Enrique Leff geradas pela articulação dos processos de ordem física, biológica, termodinâmica, econômica, política e cultura

Fonte: Autores, (2016).

$\mathrm{Na}$ aplicação in loco do questionário, os grupos foram orientados que não haveria uma resposta correta ao item, pois, tratava-se do entendimento pessoal dos entrevistados acerca do conceito.

Tabela 3. Relação dos conceitos ambientais em percepção dos discentes.

\begin{tabular}{clc}
\hline Itens & \multicolumn{1}{c}{$\begin{array}{c}\text { Visões } \\
\text { ambientais }\end{array}$} \\
\hline a & Conceito legal - P. N. M. A. - Art. 3o., I & \\
b $\quad \begin{array}{l}\text { Classificação - José Afonso da Silva } \\
\text { Meio ambiente artificial }\end{array}$ & \\
c $\quad \begin{array}{l}\text { Classificação - José Afonso da Silva } \\
\text { Meio ambiente cultural }\end{array}$ & Antropocêntrica \\
d $\quad \begin{array}{l}\text { Classificação - José Afonso da Silva } \\
\text { Meio ambiente natural ou físico }\end{array}$ & \\
e & Conceito filosófico - Enrique Leff & Ecocêntrica \\
\hline Fonte: Autores, (2016).
\end{tabular}

Fonte: Autores, (2016).
Os dois grupos revelaram uma compreensão eminentemente naturalista - Antropocêntrica - do termo, sobremaneira os calouros, que marcaram em sua maioria o item d - Meio ambiente Natural (físico). Entre os formandos os resultados foram mais distintos, ainda se revela uma posição naturalista, principalmente se somarmos os itens a $+d$, contudo, as respostas não mais se polarizaram em apenas uma proposição o que indicou uma amplitude de percepção sobre esse grupo.

Tabela 4. Distribuição da compreensão do conceito de meio ambiente.

\begin{tabular}{lllll}
$\begin{array}{l}\text { Compreensão } \\
\text { de Meio }\end{array}$ & Calouros & \multicolumn{3}{c}{ Formandos } \\
Ambiente & Frequência & $\%$ & Frequência & $\%$ \\
\hline a.Legal & 1 & 7,14 & 15 & 33,33 \\
b.Artificial & 1 & 7,14 & 1 & 2,22 \\
c.Cultural & 2 & 14,29 & 9 & 20,00 \\
d.Natural & 9 & 64,29 & 11 & 24,44 \\
e.Complexo & 1 & 7,14 & 9 & 20,00 \\
\hline Total & 14 & 100 & 45 & 100 \\
\hline
\end{tabular}

Fonte: Autores, (2016).

O item e. traz um conceito complexo de ambiente, mais elaborado e atual, proposto por Enrique Leff, representando na pesquisa uma das propostas de visão ecocêntrica ambiental que muitos teóricos apontam como necessária à crise ambiental em que passa o planeta. A percepção desse conceito entre o primeiro grupo ainda foi tímida, e mesmo no segundo grupo não se apresentou como a de maior destaque, porém, analisando comparativamente já se pôde evidenciar um desenvolvimento na percepção ambiental do aluno calouro para o aluno finalista.

\section{IV.3 PERCEPÇÃO AMBIENTAL: ALUNO X MEIO AMBIENTE X CURSO DE DIREITO.}

Um dos objetivos da pesquisa foi diagnosticar a capacidade de articulação apresentada pelos acadêmicos sobre a transversalidade dos temas ambientais e as disciplinas jurídicas cursadas. Para tanto, o estudo relacionou as proposições vinculando-as ao art. $5^{\circ}$.,II da Resolução do Conselho Nacional de Educação/ Câmara de Educação Superior (CNE/CES) no. 9 de 29 de setembro de 2004, as chamadas disciplinas do Eixo de Formação Profissional listadas na Tabela 5., e, pediu que os alunos indicassem qual ou quais delas poderiam ser estudadas com interdisciplinaridade ambiental.

Tabela 5. Relação das disciplinas do eixo de formação profissional.

Resolução do Conselho Nacional de

Educação/ Câmara de Educação Formandos Calouros

Superior (CNE/CES) no. 9 de 29 de (\%)

setembro de 2004 - Art. $5^{\circ}$.,II

\begin{tabular}{lll}
\hline Direito Constitucional & 69 & 50 \\
Direito Administrativo & 42 & 29 \\
Direito Tributário & 16 & 22 \\
Direito Penal & 36 & 29 \\
Direito Civil & 36 & 36 \\
Direito Empresarial & 33 & 22 \\
Direito do Trabalho & 16 & 4 \\
Direito Internacional & 40 & 57 \\
Direito Processual & 16 & 22 \\
\hline
\end{tabular}

Fonte: Autores ,(2016). 
Fazendo um levantamento das disciplinas apontadas nos dois extremos da pesquisa, as com mais de $50 \%$ e as com menos de $25 \%$ encontramos:

- entre os calouros: com mais de 50\% apenas as disciplinas de Direito Internacional $(57 \%)$ e Direito Constitucional $(50 \%)$ e com menos de $25 \%$ as disciplinas Direito do Trabalho (14\%), Direito Processual (22\%), Direito Empresarial (22\%) e Direito Tributário (22\%);

- entre os formandos: apenas a disciplina de Direito Constitucional obteve destaque com $69 \%$, as restantes ficaram abaixo da metade das escolhas no universo de estudo, sendo que quatro não alcançaram nem mesmo o patamar de um quarto das opções marcadas, foram elas: Direito do Trabalho, Direito Tributário e Direito Processual, todas com 16\% das opiniões.

$\mathrm{O}$ fato dos calouros serem neófitos no mundo jurídico facilita a compreensão de que apenas duas disciplinas tenham aparecido com mais ênfase de possível interdisciplinaridade, principalmente Direito Constitucional, que é uma das primeiras do eixo de formação profissional a ser inserida na grade curricular. E a publicidade das causas ambientais destacadas pela mídia nacional e internacional, talvez seja uma explicação para a disciplina Direito Internacional ter sido a primeira mais marcada pelos iniciantes.

Ainda sobre as disciplinas que apareceram em destaque, compreender a relação estreita entre Direito Constitucional e o meio ambiente, é o que se esperaria como resultado nas respostas do grupo dos finalistas e foi o que se demonstrou. Entretanto, apenas esta foi alvo de mais da metade das respostas, a porcentagem das outras disciplinas é baixa e faz deduzir que essa parcela da amostra não consegue correlacionar as demais disciplinas às questões ambientais.

Como similaridade entre os grupos foi observado que três disciplinas aparecem em menos de um quarto das opções, as disciplinas de Direito: Empresarial, Processual, Tributário e do Trabalho.

\section{IV.4 PERCEPÇÃO DAS QUESTÕES AMBIENTAIS E FORMAÇÃO ACADÊMICA.}

A última questão do instrumento de pesquisa levou os respondentes a manifestarem seu nível de concordância sobre alguns temas ambientais em relação a sua formação acadêmica e futura atuação profissional, foram chamados a optar entre uma de cinco opções que variaram entre: concordo totalmente, concordo, sem opinião, discordo e discordo totalmente.

No que diz respeito à consistência interna do questionário, os itens foram analisados estatisticamente, em grupo e item por item, seguindo a opção de cada participante, os resultados presentes na Tabela 7 revelam um Coeficiente alfa de Cronbach aproximado de 1,0 para as duas amostras, o que abona a homogeneidade tanto do constructo quanto das respostas dos participantes.

Tabela 7. Resultado da análise de confiabilidade pelo Coeficiente Alfa de Cronbach.

\begin{tabular}{lll}
\hline Grupo & Itens & Alfa \\
\hline Calouros & 14 & 0,874 \\
Formandos & 45 & 0,948 \\
\hline
\end{tabular}

Fonte: Autores, (2016).

Dos cinco itens analisados o que apresentou menor desvio padrão entre calouros e formandos foi o item "Eu também sou responsável pelo meio ambiente", demonstrando que as duas parcelas amostrais tem uma percepção que tende a uma visão mais ecocêntrica de meio ambiente percebendo-se como parte e não aparte do todo ambiental.
Entretanto, cabe destacar que os dois grupos revelaram na pesquisa uma percepção ainda muito ligada ao positivismo jurídico, pois, calouros e formandos informaram concordar com a opção "Criando mais leis ambientais o meio ambiente ficará mais protegido". Esse resultado, ainda que, aparentemente conflitante com as análises anteriores tende a apontar para a necessidade de maior inserção da prática ambiental junto a sua formação acadêmica.

Pôde ser observado nas respostas dos calouros que ao entrarem na faculdade demonstram pouco conhecimento da sua proposta ambiental, bem como, discordaram da possibilidade de vir a atuar em alguma área jurídica relativa ao meio ambiente.

Porém, o andamento do curso parece oferecer subsídios que melhoraram esse nível de percepção. É o que se abstrai entre os formandos na avaliação dos itens "Essa instituição de ensino tem preocupação com a presença da temática ambiental na grade curricular", e, "Depois de formado (a) considero atuar na área jurídica ambiental" onde os coeficientes de variação e desvio padrão apresentaram uma diminuição se comparado aos resultados obtidos com o dos calouros.

$\mathrm{O}$ item "Estudar o meio ambiente é fundamental para minha formação acadêmica" também apresentou baixos desvios e coeficientes de variação entre as duas amostras de estudo, deste resultado pode ser apurado que existe o reconhecimento da importância do estudo das temáticas ambientais durante sua formação profissional.

\section{CONCLUSÃO}

A percepção dos acadêmicos do curso de Direito analisado demonstrou-se de modo geral, satisfatória, o reconhecimento do meio ambiente no seu entorno e a importância do seu estudo esteve presente em todo o trabalho.

Porém, comparando calouros e formandos foi possível identificar que há a necessidade de observar algumas ações quanto à interdisciplinaridade curricular ambiental e a presença da forte ênfase positivista no curso, o que caracterizaria uma percepção seletiva do meio ambiente.

Concluindo, a percepção ambiental é ampliada conforme são ampliados a faixa etária e o período acadêmico, porém, a interdisciplinaridade ambiental restou carente de compreensão mesmo entre os concluintes do curso, demonstrando que a educação formal pode contribuir com a capacidade de reflexão crítica, mas precisa ser trabalhada de forma diversa aliando cada vez mais a teoria à prática, ampliando a visão dos acadêmicos, já que o objetivo é a formação de futuros profissionais aptos às diversas demandas contemporâneas.

\section{REFERÊNCIAS}

[1] Rodrigues, M.L; Malheiros, T.F.; Fernandes. V; Darós, T.D. A percepção ambiental como instrumento de apoio na gestão e formulação de políticas ambientais. Saúde e Sociedade. V.21, supl.3, Dez. 2012. p. . Disponível em: < www.scielo.br/pdf/sausoc/v21s3/09.pdf $>$. Acesso em: $31 \mathrm{de}$ julho de 2016.

[2] Jesus, A. J. F. de. Do Timor-Leste a Paraíba: percepção ambiental e as representações sociais de meio ambiente de professores e educandos do ensino médio. Dissertação (Mestrado em Educação). Universidade Federal da Paraíba. João Pessoa: PB. 2013 Disponível em: http://tede.biblioteca.ufpb.br:8080/bitstream/tede/4711/1

/ArquivoTotal.pdf. Acesso em: 15 de agosto de 2016. 
[3] Paiva, K.C.M; Lage, F.P; Santos, S.N; Silva, C.R.V. Competências profissionais e interdisciplinares no Direito: percepções de discentes de uma faculdade particular mineira. Revista Educação e Pesquisa. São Paulo, v.37, n.2, p.355-373, mai./ago. 2011. Disponível em: < http://www.scielo.br/pdf/ep/v37n2/v37n2a10.pdf >. Acesso em: 12 de junho de 2016.

[4] Brito, Fernando de Azevedo Alves. A percepção ambiental de professores e alunos e a educação ambiental no curso de direito da Faculdade $X$ : um estudo de caso no sudoeste da Bahia. 2013. p.23. Dissertação (Mestrado em Ciências Ambientais, Área de Concentração em Meio ambiente e Desenvolvimento). Universidade Estadual do Sudoeste da Bahia, Itapetinga, BA. Disponível em:< www.uesb.br/ppgca/dissertacoes/2013/fernando.pdf> Acesso em: 17 de julho de 2016.

[5] Martins, L. T. dos R. Percepção e educação ambiental: contribuições metodológicas para o estudo das relações entre áreas naturais protegidas e instituições de ensino. 2015. Tese (Doutorado em Geografia). Universidade Estadual Paulista Júlio de Mesquita Filho. Rio Claro: SP. Disponível:< http://www.athena.biblioteca.unesp.br/exlibris/bd/cathedra/0305-016/000864727.pdf>. Acesso: 20 de agosto de 2016.

[6] Oliveira, J. E. F. Percepção e ações educativas em ambientes escolares: enfoques aos documentos legais determinantes em área de proteção ambiental. 2013. Dissertação (Mestrado em Desenvolvimento e Meio Ambiente). Universidade Federal do Rio Grande do Norte. Natal : RN. Disponível em: http://repositorio.ufrn.br:8080/jspui/handle/123456789/18242>. Acesso em: 18 de agosto de 2016.

[7] Derani, Cristiane. Direito Ambiental Econômico. São Paulo: Saraiva, $3^{\text {a }}$. ed. 2008. p.02-03.

[8] LEFF, Enrique. Saber ambiental: sustentabilidade, racionalidade, complexidade, poder. Petrópolis, RJ: Vozes, 2001. p.13.

[9] Sparenberg, R.F.L.; Silva, D.A.da. A relação, meio ambiente, desenvolvimento e o papel do direito ambiental. Revista Veredas do Direito. Escola Superior Dom Helder Câmara. Belo Horizonte, v.2, n.4, p.89, Julho-Dezembro. 2005. Disponível

<www.domhelder.edu.br/veredas_direito/pdf/22_109.pdf>.

Acesso em: 16 de junho de 2016.

[10] Benjamin, A.H. A Natureza no Direito Brasileiro: coisa, sujeito ou nada disso. Revista do Programa de Pós-Graduação em Direito da UFC. Vol31. N.1. jan - jun, 2011. p. 79 - 96. Disponível em: $\quad$ http://www.periodicos.ufc.br/index.php /nomos/article /view/398/380>. Acesso em: 18 de agosto de 2016.

[11] Andrade,Carolina Machado; Bonfim, Priscila Hélen Guimaraes; Costa, Jackson Fagner de Assis ; Ruas,Heloísa de Amorim Artacho; SANTOS, Maria Luiza Ramirez; Torres, Vânia. Perfil dos acadêmicos do 10 período do curso de direito de uma instituição particular de ensino superior, face às novas exigências do profissional de direito na autalidade. In: Rev. Multitexto, Minas Gerais, v.2, n.01, p. 50-55, out/2013. Disponível em:< issuu.com/eadunimontes/docs/completo_multitexto>. Acesso em: 12 de agosto de 2016.
[12] Oliveira, J.C. Autonomia do Direito Ambiental: Necessidade da sua obrigatoriedade no ensino jurídico brasileiro ante a sociedade de risco. Dissertação (Mestrado em Relações Sociais e Novos Direitos, Subárea Núcleo Interdisciplinar de Pesquisa e Extensão em Direito Ambiental e Direito Animal). Universidade Federal da Bahia. Salvador, BA. 2011. p.28. Disponível em: < http://www.repositorio.ufba.br/ri/handle/ri/10715> Acesso em: 26 de julho de 2016.

[13] Marocco, A. de A. L. Ensino jurídico no Brasil: desafios à formação do profissional do Direito no Século XXI. 2011. p. 97. Dissertação (Mestrado em Direito). Universidade Federal de Santa Catarina. Florianópolis: SC. Disponível em: https://repositorio.ufsc.br/xmlui/bitstream/handle/123456789/947 58/299272.pdf?sequence $=1 \&$ isAllowed $=y>$ Acesso em: $28 \mathrm{de}$ julho de 2016.

[14] Junior, S.D. da S.; Costa, F.J. Mensuração e e escalas de verificação: uma análise comparativa das escalas de Likert e Phrase Completion. PMKT Revista Brasileira de Pesquisas de Marketing, Opinião e Mídia. V.15, p. 1-16, outubro, 2014. Disponível em: www.revistapmkt.com.br. Acesso: 02 de setembro de 2016.

[15] BRASIL. Resolução CNE/CES no 9/2004. 2004. Disponível

em:<http://www.portal.mec.gov.br/cne/arquivos/pdf/rces09_04.p df $>$. Acesso em: 20 de julho de 2016. 